\title{
Pitarch, Pedro y Julián López García (Editores), 2001, Los Derechos Humanos en tierras mayas. Politica, representaciones y moralidad, Sociedad Española de Estudios Mayas, Madrid.
}

S i bien es cierto a lo largo de la historia, desde las civilizaciones antiguas, se pronunciaron sentencias y planteamientos tendientes al reconocimiento y valoración de los seres humanos, pero en 1948, con la "Declaración Universal de los Derechos Humanos", es cuando se elabora de manera más concreta y formal una serie de prerrogativas inherentes al individuo para garantizar un mejor desarrollo de éste en cualquier sociedad.

Dichas prerrogativas son resultado de un contexto político, económico, social y cultural de determinada época que no puede dejar de lado un trasfondo histórico, así como la influencia, de ideas liberales de la Ilustración.

De esta manera, desde su surgimiento hasta nuestros días, los derechos humanos han tenido la intención, entre otras cosas, de contribuir a un desarrollo integral de los individuos partiendo del reconocimiento de la dignidad intrínseca y de los derechos iguales e inalienables de cada persona. Es decir, parte de la valoración del hombre en tanto ser humano, que equivale a ubicarnos en una situación de iguales eliminando así todo tipo de discriminación y malos tratos.

Por ello también los derechos humanos son universales aplicables a toda persona sin importar sexo, edad, posición social, partido político, creencia religiosa, origen familiar o condición económica. De la misma manera promueven también el individualismo en tanto que pretenden mantener las mejores condiciones para cada individuo.
El discurso es muy prometedor, sin embargo, al tratar de confrontarlo con las actuales condiciones de vida en determinadas regiones de un país, se encuentran múltiples problemáticas que nos hacen cuestionar la eficacia y universalidad que en un momento dado puede tener dicho discurso. Por ejemplo, ¿cómo aplicar los conceptos de dignidad e igualdad entre todos en comunidades en las que tanto niños como mujeres son concebidos como seres inferiores?; y ¿cómo defender los derechos de cada individuo en particular cuando en dichas comunidades se piensa realmente en términos de "comunidad" en sentido estricto?

A partir de este tipo de reflexiones nace el libro: Los derechos humanos en tierras mayas. Politica, representaciones $y$ moralidad, en el que se conjugan trabajos de varios investigadores referentes a los Derechos Humanos en la zona Maya, específicamente regiones de Chiapas y Guatemala, que a pesar de ser regiones de países distintos comparten un pasado histórico, y condiciones geográficas y culturales semejantes.

La importancia de esta obra radica en el hecho de analizar la aplicación de los Derechos Humanos en regiones concretas; de evitar todo tipo de prejuicios ya sea a favor o en contra; y, simplemente, de hablar de los resultados y de las muy concretas problemáticas que de esta aplicación, surgen.

El libro está dividido en tres apartados: política, representaciones y moral; como los ejes temáticos a partir de los cuales se abordan los Derechos Humanos. 
Esta división no implica que cada ensayo sea totalmente independiente de cualquier otra temática, sino por el contrario: cualquier ensayo puede tener tintes políticos y éticos conjuntamente, o estar interrelacionados entre sí; sin embargo, se han clasificado de acuerdo a la temática que abordan con mayor fuerza.

En la introducción, Rafael del Águila plantea de manera general algunos de los problemas que se presentan en la aplicación de los Derechos Humanos; señala el problema del universalismo frente a la diversidad cultural; y anota la necesidad de un proyecto político que incluya ambas posturas sin que lleguen a ser excluyentes, es decir, que la diversidad cultural no implique negar la universalidad de las sentencias planteadas y viceversa.

En el apartado de política, se analiza las relaciones de conflicto, negociación y ayuda que se establece entre el Estado y organizaciones internacionales con el mundo indígena. Dicho apartado se conforma de cuatro ensayos en los que se alude al hecho de que los Derechos Humanos son claramente cargados de una ideología política que muchas veces toma partido; que suele cobrar cierto sentido para el gobierno y cierto sentido para los indígenas, quienes también han tomado el discurso como escudo en algunos conflictos.

Así, Roberto Carmack nos da una perspectiva de los Derechos Humanos, su ideología y sus implicaciones políticas en Guatemala a través de un recorrido histórico. Rachel Sieder y Jessica Witchell analizan cómo las organizaciones indígenas en Guatemala han recurrido a un discurso imaginario del indígena como método de defensa de su propia identidad. Mientras que Xochitl Leyva y Shannon Speed, por un lado; y David Stoll, por otro, tratan sobre la interacción, interpretación y participación de los Derechos Humanos en las situaciones de conflicto armado de las poblaciones indígenas y el gobierno de Chiapas y Guatemala respectivamente, así como las implicaciones que esto ha tenido en tales poblaciones.
En cuanto a las cuestiones sobre interpretación, uso y sentido de los Derechos Humanos en poblaciones indígenas, particularmente de Chiapas y Guatemala, son tratadas con mayor profundidad en el apartado de representaciones.

Pedro Pitarch comienza con una traducción al tzeltal —una lengua maya de Chiapas — de una parte de los Derechos Humanos en la que se presenta una serie de problemáticas al tratar de adaptar ciertos términos occidentales a una lengua en la que dichos términos en realidad no existen o no tienen la misma significación, por lo que se recurre a hacer cambios para que tales sentencias puedan cobrar un sentido entre la población tzeltal.

Stener Ekern nos muestra en su artículo los conflictos ocasionados al confrontar la tradición jurídica oral y local de una comunidad k' iche en Guatemala y el sistema internacional de los Derechos Humanos. Julián López García estudia la manera como las organizaciones gubernamentales y no gubernamentales tratan de extender y difundir el discurso mediante la capacitación en los diversos rincones de Guatemala, particularmente la zona Ch'orti', y cómo esto genera conflictos y reproduce también errores al verse como un bien incuestionable impidiendo así cualquier tipo de diálogo. Marta Elena Casaús discute sobre la reformulación de las identidades étnicas a partir de los Acuerdos de Paz en Guatemala.

Finalmente, en el apartado de moralidad, se le da mayor énfasis a la parte ética en el estudio de los usos e implicaciones que han tenido los Derechos Humanos. Por una parte se hace alusión a cierto tipo de violaciones a los derechos que no sólo se traducen en detención arbitraria, tortura, abuso de la autoridad, etc., sino que también implican pobreza, discriminación y marginación. Amanda Pop Bol, por ejemplo, examina el caso concreto de Pedro Rax Cucul en el que se denota un desprecio a la vida y un racismo, que finalmente nos da cuenta de éste y la injusticia social persistentes en los 
grupos dominantes hacia los llamados grupos vulnerables. Christine Kovic nos habla de las concepciones de los Derechos Humanos de una comunidad católica de Chiapas, y Mario H. Ruz nos muestra el papel que desempeñaron las mujeres mayas en la construcción de su propia historia, a pesar de las adversidades que se les presentaron.

Dentro del mismo apartado se analizan los aspectos éticos implicados en la labor antropológica. Edgar F. Fischer nos indica tales implicaciones éticas en la labor, tanto académica como de campo, de los antropólogos; así como su dificultad en la práctica a partir del análisis de los casos concretos de guatemaltecos. Brent E. Metz plantea los paradigmas antropológicos a los que se enfrentan los investigadores, estudiando particularmente el caso de un antropólogo que colabora con un movimiento indígena Ch'orti'.

En el epílogo, Rodolfo Stavenhagen escribe sobre la necesidad e importancia del respeto y reconocimiento, tanto de los derechos individuales como de los derechos colectivos.
De esta manera, la propuesta de este libro es fructífera en tanto nos presenta un análisis de los distintos usos, interpretaciones, problemáticas, conflictos e implicaciones que tienen los Derechos Humanos en tierras mayas, particularmente de las regiones de Chiapas y Guatemala, como ya se mencionó.

Además de tener objetividad, al evitar todo tipo de prejuicios, se centra en la disertación de la importancia de un trabajo etnográfico y académico capaz de aportar resultados concretos que, más allá de un sentido peyorativo, nos dé cuenta de las contradicciones dentro del discurso o quizá de los errores y violaciones en la aplicación de estos derechos.

Finalmente, no se trata de descartar o invalidar la "Declaración Universal de los Derechos Humanos", sino más bien de evaluar resultados con la intención de impulsar su mejor aplicación que no implique violación a la integridad de la identidad de las poblaciones indígenas; y de conjuntar, como se ha señalado, estas prerrogativas de carácter universal con las múltiples implicaciones que tiene la diversidad cultural.

Verónica Yhasmín López Muñoz, Estudiante de licenciatura en filosofía de la U de G 